\title{
Validating efficacy of Sericocomopsis hildebrandtii, Carissa edulis, and Ximenia americana in treating Taenia solium cysticercosis in pigs: A randomized controlled trial
}

\author{
Mwemezi L. Kabululu ${ }^{1, *}$ (D) and Mathias E. Boa ${ }^{2}$ \\ ${ }^{1}$ Tanzania Livestock Research Institute (TALIRI) - Uyole, Mbeya, Tanzania, and ${ }^{2}$ Independent Researcher, Morogoro, \\ Tanzania \\ ${ }^{\star}$ Corresponding author. Email: address-mwemezie@gmail.com
}

(Received 18 May 2021; Revised 19 October 2021; Accepted 03 November 2021)

\begin{abstract}
Ethnoveterinary use of plants dates back to ancient times. This study aimed to validate purported efficacy of Sericocomopsis hildebrandtii and a concoction of Carissa edulis and Ximenia americana in treating Taenia solium cysticercosis in pigs. Twenty-four infected pigs were randomly allocated to T1, T2, and T0 groups, each with eight pigs. Each T1 pig was provided with $8 \mathrm{~g}$ of $S$. hildebrandtii root powder, whereas each T2 pig was given $8 \mathrm{~g}$ of the concoction. T0 was a control. The pigs were slaughtered 16 weeks post treatment and carcase dissections were performed to establish cyst numbers. T1 cyst numbers were significantly lower than those of T0 $(p=.004)$ and T2 $(p=.013)$. No difference was observed between T2 and T0. This study validated efficacy of S. hildebrandtii but not of X. americana and C. edulis. Further studies are necessary for validation and documentation of plants of ethnoveterinary importance.
\end{abstract}

Key words: cysticercosis; ethnoveterinary; pigs; plants; Taenia solium

\section{Introduction}

From time immemorial, medicinal plants have been used to control diseases and parasites of humans and animals (Athanasiadou et al., 2007; Thirumalai et al., 2009). However, much of the evidence of the medicinal potencies of plants has been based on anecdotal observations and reports with no corroboration from experimental trials (Athanasiadou et al., 2007; McGaw \& Eloff, 2008). In some other cases, there has been a disparity between ethnoveterinary reports and results of experimental trials (Costa et al., 2006; Githiori et al., 2004). This study was carried out to investigate efficacy of three plants against Taenia solium (porcine) cysticercosis in pigs.

T. solium is considered a foodborne parasite with the highest burden globally (Torgerson et al., 2015). It causes neurocysticercosis, the major cause of acquired epilepsy in endemic areas (Mwape et al., 2013; 2015; Ndimubanzi et al., 2010). As infected pork plays an important role in the transmission of the parasite, treatment of infected pigs is instrumental in breaking life cycle of the parasite. To that effect, two herbalists in Mbulu district in north-eastern Tanzania claimed to have a knowledge of plants available in their localities, which treat porcine cysticercosis. One herbalist recommended a plant known as "gwaway" in iraqw, the local vernacular; and another recommended a concoction of two plants, "titiwi" and "ma'ayangu".

\footnotetext{
( $)$ The Author(s), 2021. Published by Cambridge University Press. This is an Open Access article, distributed under the terms of the Creative Commons Attribution licence (http://creativecommons.org/licenses/by/4.0), which permits unrestricted re-use, distribution and reproduction, provided the original article is properly cited.
} 
Hence, this experimental study was carried out to confirm the purported efficacy of the plants in treating T. solium cysticercosis in naturally infected pigs. We envisage that the findings of this study will prompt further research on other plants of ethnoveterinary importance in Tanzania and elsewhere.

\section{Methods}

\subsection{Study area}

The plants were sourced from Mbulu District $\left(3.80^{\circ}-4.50^{\circ} \mathrm{S} ; 35.00^{\circ}-36.00^{\circ} \mathrm{E}\right)$ in Manyara Region, northeastern Tanzania, where T. solium infections have been reported to be endemic (Boa et al., 1995; Mwang'onde et al., 2018; Ngowi et al., 2004; Ngowi et al., 2010). Study animals were collected from Mbozi District, in south-western Tanzania. The trial was carried out at the Tanzania Livestock Research Institute (TALIRI), Southern Highlands Zone, at Uyole, Mbeya Region.

\subsection{Preparation of plant extracts}

Mature plants were uprooted, thoroughly washed, and the roots were chopped into small pieces which were then dried in a shade for about 10 days. Dried root pieces were ground into powder and was then stored in air-tight containers until use. For the purpose of botanical identification, branches with leaves and flower fluoresces were collected and sent to the Department of Forest Biology, Sokoine University of Agriculture, Morogoro.

\subsection{Study animals}

Slaughter-age pigs suspected to be infected with T. solium cysts were examined for presence of palpable lingual nodules as described by Gonzalez et al. (1990) and Ngowi et al. (2004) (Figure 1). After a pig was confirmed to be infected, a consent to sell the pigs was sought from the owner. Twenty-four pigs were eventually bought and were transported to TALIRI-Uyole, where they were kept for 2 weeks for acclimatization before the onset of treatment. The pigs were provided with a compounded pig feed two times a day, in the morning and in the evening. Water was provided ad libitum.

\subsection{Study design and treatment of animals}

This study adopted a randomized controlled trial design, where the 24 infected pigs were randomly allocated to three groups (T1, T2, and T0) of eight animals each. Each group was housed in a separate pen. Eight grams of "gwaway" (mixed with small amount of feed) were provided to each pig in the T1 group, at days 0,7 , and 14 . The same dosing regimen was used for pigs in the T2 group provided with a concoction of "titiwi" and "ma'ayangu" (4 $\mathrm{g}$ of each). T0 served as control.

\subsection{Pig slaughter, pork inspection, and carcase dissection procedures}

nce the onset of the trial, the pigs were slaughtered. Routine meat inspection was performed using general provisions and guidelines for pork inspection in Tanzania (Government of Tanzania, 1993).

After the pork inspection, the brain, tongue and heart with psoas, masseters (internal and external) and Triceps brachii muscles were extracted. Previous studies have indicated these organs and muscles groups to be predilection sites for T. solium cysts (Boa et al., 2002; Sciutto et al., 1998). Cyst counting was done by slicing the extracted organs/muscle groups using fine cuts $(<5 \mathrm{~mm})$. Cysts were classified as viable or degenerated/calcified, according to Boa et al. (2002). 


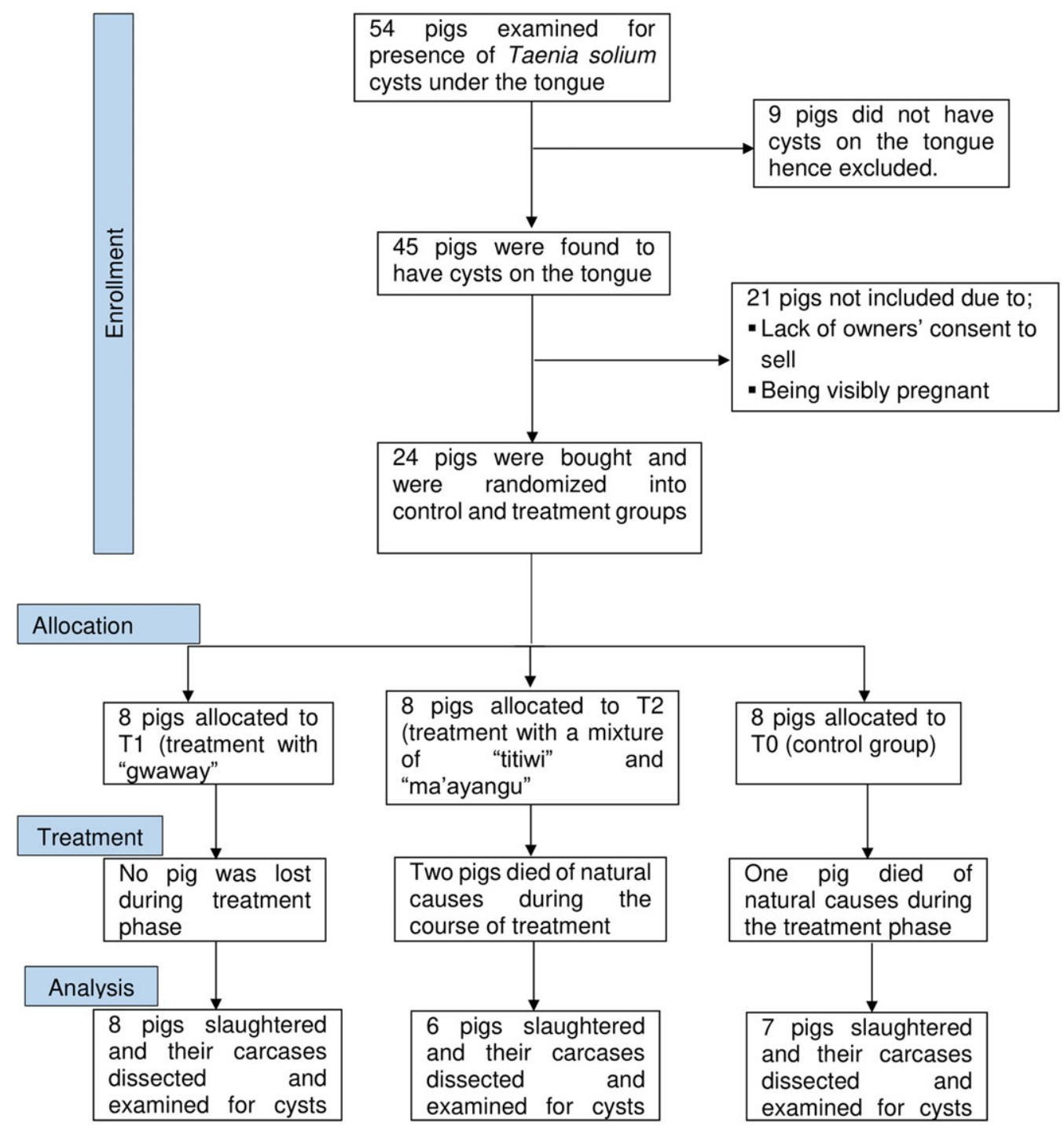

Figure 1. Flow of study units during the experimental trial.

\subsection{Ethical considerations}

The study protocol was approved by scientific committee of the Zonal Agricultural Research and Development Fund (ZARDEF) of the Southern Highlands Zone (Ref. No. SHZARDEF/LP/10/02). Animal welfare regulations as stipulated in the section 40 of the Tanzania's Animal Welfare Act number 19 of 2008 were strictly complied with. Pig owners provided an informed verbal consent to allow their pigs to be examined, and decision to sell a pig relied solely on a farmer's willingness to sell.

\subsection{Data analysis}

Data were analyzed using STATA ${ }^{\odot}$ (StataCorp, 2001. Stata Statistical Software, Release 12.0. Stata Corporation 2011, College Station, TX). A difference in cyst numbers between groups was tested for significance using a Kruskal-Wallis $H$ test. Dunn's test was used for post hoc pairwise comparisons with Bonferroni adjustments. Level of significance was set at $5 \%$. 


\section{Results}

\subsection{Botanical identification of the plants}

"Gwaway" was identified as Sericocomopsis hildebrandtii under the family Amaranthaceae, whereas

"Titiwi" and "Ma'ayangu" were identified as Carissa edulis and Ximenia americana under families Apocynaceae and Olacaceae, respectively. The plant names were checked with http://www.theplantlist. org (website accessed on November 25, 2020).

\subsection{Clinical observations}

No visible clinical adverse reactions were noted as the effect of the herbal materials. However, three pigs, one from the T2 group and two from the control group died during the course of the trial, but the deaths were confirmed to be caused by sources other than the effect of the herbal materials.

\subsection{Pork inspection and carcase dissection}

After inspection, the meat from all eight $\mathrm{T} 1$ pigs was judged to be clean and aesthetically acceptable to a consumer and all the carcases were therefore passed for human consumption, except for the brain of four pigs. In contrast, the inspector found all the carcases belonging to the $\mathrm{T} 0$ and $\mathrm{T} 2$ groups unfit for human consumption and were all condemned.

The recorded numbers of viable and calcified cysts in all slaughtered pigs are shown in Table 1. Overall, mean cyst numbers were highest in the control group $(1,081 \pm 1,372)$, and lowest in the T1 (S. hildebrandtii) group $(16 \pm 25)$ (Table 2$)$. All cysts in T1 pigs were located solely in the brain tissues of four pigs and were all viable (Table 1). In T2 pigs, $92.3 \%$ of all cysts were viable while all cysts in the control group were viable. In both T2 and control groups, cysts were distributed in all dissected organs and muscle groups.

Kruskal-Wallis $H$ test indicated that there was a significant difference in cysts counts between the groups $\left(\chi_{2}(2)=11.3, p=.004\right)$ with mean ranks of 42,84 , and 105 for T1, T2, and T0, respectively. Dunn's test for post hoc pairwise comparisons with Bonferroni adjustments indicated that T1 mean rank cyst count was significantly lower than that of the control group $(p=.004)$; and of the T2 $(p=.013)$. However, mean rank of T2 was not significantly different from that of T0 (Figure 2).

\section{Discussion}

This study showed that $S$. hildebrandtii was efficacious in treating pigs naturally infected with $T$. solium cysts, with no visible side effects. The plant material cleared all cysts from all examined predilection sites with no traces of visible degenerated/calcified cysts. The meat was also aesthetically clean and was passed for human consumption with no conditions. Therefore, these findings corroborate and validate the anecdotal reports regarding the plant's efficacy.

However, S. hildebrandtii was not able to clear brain cysts in four pigs. Limited efficacy on brain cysts has been reported in previous studies with oxfendazole-a benzimidazole reported to be effective against porcine cysticercosis (Gonzalez et al., 1998; Gonzalez et al., 2012; Mkupasi et al., 2013; Pondja et al., 2012; Sikasunge et al., 2008). Infected brain can pose a risk of infection to consumers, because the brain is not included in the routine inspection of pork. However, consumption of undercooked or raw pig brain has been reported to be relatively uncommon in endemic areas (Gonzalez et al., 1998). Thus, it is highly improbable that the cysts that survive only in the brain will perpetuate the parasite's transmission.

The results showed that the concoction of X. americana and C. edulis reduced cyst counts, but the reduction was not statistically significant. The divergent results underscore the importance of validating indigenous ethnoveterinary knowledge.

Use of S. hildebrandtii can provide an affordable and an alternative option to oxfendazole. A recent field trial in Mbeya and Mbozi districts in Tanzania has shown promising results with the use of oxfendazole 
Table 1. Taenia solium cyst numbers in selected organs and muscle groups of 21 slaughtered pigs, 8 from T1 group treated with Sericocomopsis hildebrandtii, 6 of T2 treated with a concoction of Carissa edulis and Ximenia Americana, and 7 which served as a control.

\begin{tabular}{|c|c|c|c|c|c|c|c|c|c|c|c|c|c|c|}
\hline \multirow[b]{2}{*}{ Group } & \multirow[b]{2}{*}{ Pig no. } & \multirow[b]{2}{*}{ Total cyst count } & \multicolumn{2}{|c|}{ Heart } & \multicolumn{2}{|c|}{ Tongue } & \multicolumn{2}{|c|}{ Psoas } & \multicolumn{2}{|c|}{ Masseter } & \multicolumn{2}{|c|}{ Triceps brachii } & \multicolumn{2}{|c|}{ Brain } \\
\hline & & & Via. & Calc. & Via. & Calc. & Via. & Calc. & Via. & Calc. & Via. & Calc. & Via. & Calc. \\
\hline \multirow[t]{8}{*}{ T1: Sericocomopsis hildebrandtii } & 2 & 30 & 0 & 0 & 0 & 0 & 0 & 0 & 0 & 0 & 0 & 0 & 30 & 0 \\
\hline & 21 & 0 & 0 & 0 & 0 & 0 & 0 & 0 & 0 & 0 & 0 & 0 & 0 & 0 \\
\hline & 24 & 0 & 0 & 0 & 0 & 0 & 0 & 0 & 0 & 0 & 0 & 0 & 0 & 0 \\
\hline & 6 & 0 & 0 & 0 & 0 & 0 & 0 & 0 & 0 & 0 & 0 & 0 & 0 & 0 \\
\hline & 23 & 3 & 0 & 0 & 0 & 0 & 0 & 0 & 0 & 0 & 0 & 0 & 3 & 0 \\
\hline & 8 & 31 & 0 & 0 & 0 & 0 & 0 & 0 & 0 & 0 & 0 & 0 & 31 & 0 \\
\hline & 3 & 69 & 0 & 0 & 0 & 0 & 0 & 0 & 0 & 0 & 0 & 0 & 69 & 0 \\
\hline & 7 & 0 & 0 & 0 & 0 & 0 & 0 & 0 & 0 & 0 & 0 & 0 & 0 & 0 \\
\hline \multirow[t]{6}{*}{ T2: Carissa edulis and Ximenia americana } & 22 & 59 & 17 & 0 & 18 & 0 & 6 & 0 & 3 & 0 & 14 & 0 & 1 & 0 \\
\hline & 10 & 395 & 43 & 3 & 84 & 2 & 79 & 0 & 53 & 0 & 122 & 0 & 9 & 0 \\
\hline & 18 & 66 & 23 & 0 & 17 & 0 & 14 & 0 & 8 & 0 & 4 & 0 & 0 & 0 \\
\hline & 9 & 92 & 0 & 0 & 53 & 7 & 9 & 0 & 10 & 0 & 9 & 0 & 4 & 0 \\
\hline & 11 & 450 & 40 & 0 & 97 & 0 & 132 & 0 & 65 & 0 & 109 & 0 & 7 & 0 \\
\hline & 12 & 123 & 0 & 25 & 2 & 17 & 17 & 9 & 2 & 15 & 22 & 13 & 1 & 0 \\
\hline \multirow[t]{7}{*}{ T0: Control } & 1 & 1,746 & 222 & 0 & 533 & 0 & 405 & 0 & 119 & 0 & 400 & 0 & 67 & 0 \\
\hline & 19 & 1,975 & 0 & 0 & 158 & 0 & 690 & 0 & 517 & 0 & 603 & 0 & 7 & 0 \\
\hline & 17 & 3,535 & 115 & 0 & 610 & 0 & 1,460 & 0 & 205 & 0 & 1,126 & 0 & 19 & 0 \\
\hline & 20 & 38 & 2 & 0 & 13 & 0 & 15 & 0 & 6 & 0 & 2 & 0 & 0 & 0 \\
\hline & 15 & 101 & 18 & 0 & 38 & 0 & 12 & 0 & 4 & 0 & 21 & 0 & 8 & 0 \\
\hline & 16 & 13 & 2 & 0 & 2 & 0 & 5 & 0 & 2 & 0 & 0 & 0 & 2 & 0 \\
\hline & 13 & 161 & 27 & 0 & 35 & 0 & 25 & 0 & 30 & 0 & 37 & 0 & 7 & 0 \\
\hline
\end{tabular}

Abbreviations: Calc., calcified/degenerated cysts; Via., viable cysts. 
Table 2. Mean, minimum and maximum numbers of Taenia solium cysts of 21 slaughtered pigs, 8 from T1 group treated with Sericocomopsis hildebrandtii, 6 of T2 group treated with a concoction of Carissa edulis and Ximenia americana, and 7 pigs of a control group.

\begin{tabular}{lcccc}
\hline Treatment group & Mean & Std. Dev. & Min. & Max. \\
\hline T1: Sericocomopsis hildebrandtii & 16.6 & 25.1 & 0 & 69 \\
\hline T2: Carissa edulis and Ximenia americana & 197.5 & 176.6 & 59 & 450 \\
\hline T0: Control & 1081.3 & $1,372.3$ & 13 & 3,535 \\
\hline
\end{tabular}

Abbreviations: Max, maximum number of cysts; Mean, mean number of cysts; Min, minimum number of cysts; $n$, number of examined pigs; Std. Dev., standard deviation of the mean.

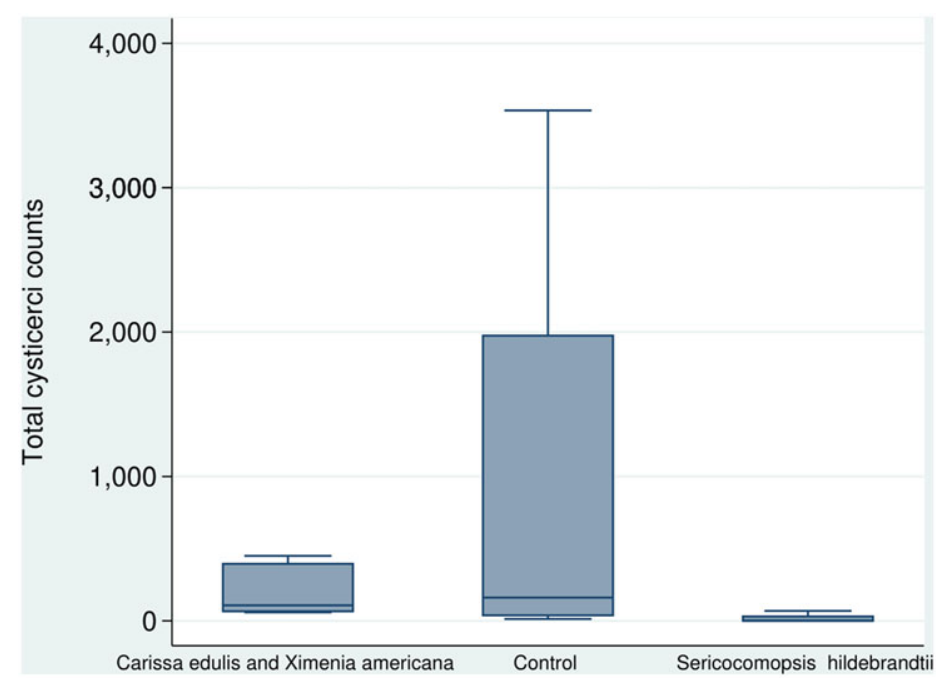

Figure 2. A box plot showing total cyst counts of 21 pigs treated with Sericocomopsis hildebrandtii (8 pigs), a concoction of Carissa edulis and Ximenia americana (7 pigs), and a control group (6 pigs).

(Kabululu et al., 2020). However, although the drug has already been registered for use in Tanzania, it is yet to be available in the market. Hence, until oxfendazole becomes readily accessible to pig farmers, S. hildebrandtii can provide a solution against porcine cysticercosis in endemic areas in Tanzania.

Ethnoveterinary medicine is largely based on indigenous knowledge which is transferred orally rather than in writing (Bullitta et al., 2018; Chinsembu et al., 2014). As a result, a great wealth of the knowledge remains undocumented and is therefore faced with a risk of becoming irretrievably lost to future generations due to rapid increase in urbanization and acculturation (Mahwasane et al., 2013; McGaw \& Eloff, 2008; van Wyk \& van Staden, 2002). Therefore, there is a pressing need to systematically record and document indigenous knowledge on ethnopharmacological use of plants, which should form a basis for their conservation. This study, therefore, apart from validating the efficacies of the plants, it contributes to the documentation of indigenous knowledge on medicinal plants. We advocate for further ethnobotanical surveys, ethnopharmacological studies and development of ethnoveterinary pharmacopoeia.

This study is not without limitations. The treatments relied on prescriptions by the herbalists. It would have been interesting to observe the effect of different parts of the plants; and different dosing regimens in dose-response trial set-ups, for more informed inferences.

\section{Conclusion}

In conclusion, this experimental trial has validated purported efficacy of S. hildebrandtii against T. solium cysticercosis in naturally infected pigs. However, the study failed to demonstrate purported efficacy of a 
concoction of X. americana and C. edulis. The results highlight the importance of validating indigenous knowledge of ethnoveterinary use of plants. Further studies are necessary to validate, document, and conserve plants of ethnoveterinary importance.

Acknowledgments. The authors are indebted to the herbalists, Mr. Damiano Safari and Mr. Abogast Ako'onay for sharing their ethnoveterinary knowledge, and for helping with preparation of the herbal extracts. We also acknowledge the expertise offered by Professor R.P.C. Temu of SUA, in the botanical identification of the plants. We also thank Mr. Joseph Mlay (RIP) for helping with implementation of the trial and carcase dissections; and Mr. Felician Makiriye for conducting the pork inspection.

Funding Statement. This study was funded by the Government of Tanzania through the Zonal Agricultural Research and Development Fund (ZARDEF), under the Agricultural Sector Development Program Phase I (ASDP I).

Conflict of Interest. The authors have no conflicts of interest to declare.

Authorship Contributions. M.E.B. conceived and designed the study. M.E.B. collected plant materials. M.E.B. and M.L.K. collected infected pigs. M.E.B. and M.L.K. performed the experiments. M.L.K. performed data analysis and drafted the manuscript. M.E.B. and M.L.K. approved the final draft.

Data Availability Statement. All data are available in this paper.

\section{References}

Athanasiadou, S., Githiori, J., \& Kyriazakis, I. (2007). Medicinal plants for helminth parasite control: Facts and fiction. Animal: An International Journal of Animal Bioscience, 1, 1392-1400.

Boa, M. E., Bøgh, H. O., Kassuku, A. A., \& Nansen, P. (1995). The prevalence of Taenia solium metacestodes in pigs in northern Tanzania. Journal of Helminthology, 69, 113.

Boa, M. E., Kassuku, A. A., Willingham, A. L., Keyyu, J. D., Phiri, I. K., \& Nansen, P. (2002). Distribution and density of cysticerci of Taenia solium by muscle groups and organs in naturally infected local finished pigs in Tanzania. Veterinary Parasitology, 106, 155-164.

Bullitta, S., Re, G. A., Manunta, M. D. I., \& Piluzza, G. (2018). Traditional knowledge about plant, animal, and mineral-based remedies to treat cattle, pigs, horses, and other domestic animals in the Mediterranean island of Sardinia. Journal of Ethnobiology and Ethnomedicine, 14, 50.

Chinsembu, K. C., Negumbo, J., Likando, M., \& Mbangu, A. (2014). An ethnobotanical study of medicinal plants used to treat livestock diseases in Onayena and Katima Mulilo, Namibia. South African Journal of Botany, 94, 101-107.

Costa, C. T. C., Bevilaqua, C. M. L., Maciel, M. V., Camurça-Vasconcelos, A. L. F., Morais, S. M., Monteiro, M. V. B., Farias, V. M., da Silva, M. V., \& Souza, M. M. C. (2006). Anthelmintic activity of Azadirachta indica A. Juss against sheep gastrointestinal nematodes. Veterinary Parasitology, 137, 306-310.

Githiori, J. B., Höglund, J., Waller, P. J., \& Baker, R. L. (2004). Evaluation of anthelmintic properties of some plants used as livestock dewormers against Haemonchus contortus infections in sheep. Parasitology, 129, 245-253.

Gonzalez, A. E., Bustos, J. A., Jimenez, J. A., Rodriguez, M. L., Ramirez, M. G., Gilman, R. H., Garcia, H. H., \& Peru, T. C. W. G. (2012). Efficacy of Diverse antiparasitic treatments for cysticercosis in the pig model. American Journal of Tropical Medicine and Hygiene, 87, 292-296.

Gonzalez, A. E., Cama, V., Gilman, R. H., Tsang, V. C. W., Pilcher, J. B., Chavera, A., Castro, M., Montenegro, T., Verastegui, M., Miranda, E., \& Bazalar, H. (1990). Prevalence and comparison of serologic assays, necropsy, and tongue examination for the diagnosis of porcine cysticercosis in Peru. The American Journal of Tropical Medicine and Hygiene, 43, 194-199.

Gonzalez, A. E., Falcon, N., Gavidia, C., Garcia, H. H., Tsang, V. C., Bernal, T., Romero, M., \& Gilman, R. H. (1998). Timeresponse curve of oxfendazole in the treatment of swine cysticercosis. The American Journal of Tropical Medicine and Hygiene, 59, 832-836.

Government of Tanzania. (1993). The food (control of quality, treatment and disposal of unfit food) regulations. The Tanzania Government Notice No. 82 (pp. 217-235) [Regulation].

Kabululu, M. L., Ngowi, H. A., Mlangwa, J. E. D., Mkupasi, E. M., Braae, U. C., Colston, A., Cordel, C., Poole, E., Stuke, K., \& Johansen, M. V. (2020). TSOL18 vaccine and oxfendazole for control of Taenia solium cysticercosis in pigs: A field trial in endemic areas of Tanzania. PLOS Neglected Tropical Diseases, 14, e0008785.

Mahwasane, S. T., Middleton, L., \& Boaduo, N. (2013). An ethnobotanical survey of indigenous knowledge on medicinal plants used by the traditional healers of the Lwamondo area, Limpopo province, South Africa. South African Journal of Botany, 88, 69-75.

McGaw, L. J., \& Eloff, J. N. (2008). Ethnoveterinary use of southern African plants and scientific evaluation of their medicinal properties. Journal of Ethnopharmacology, 119, 559-574. 
Mkupasi, E. M., Ngowi, H. A., Sikasunge, C. S., Leifsson, P. S., \& Johansen, M. V. (2013). Efficacy of ivermectin and oxfendazole against Taenia solium cysticercosis and other parasitoses in naturally infected pigs. Acta Tropica, 128, 48-53.

Mwang'onde, B. J., Chacha, M. J., \& Nkwengulila, G. (2018). The status and health burden of neurocysticercosis in Mbulu district, northern Tanzania. BMC Research Notes, 11, 890.

Mwape, K. E., Blocher, J., Wiefek, J., Schmidt, K., Dorny, P., Praet, N., Chiluba, C., Schmidt, H., Phiri, I., Winkler, A., \& Gabriël, S. (2015). Prevalence of neurocysticercosis in people with epilepsy in the Eastern Province of Zambia. PLOS Neglected Tropical Diseases, 9, e0003972.

Mwape, K. E., Phiri, I. K., Praet, N., Speybroeck, N., Muma, J. B., Dorny, P., \& Gabriël, S. (2013). The incidence of human cysticercosis in a rural community of Eastern Zambia. PLOS Neglected Tropical Diseases, 7, e2142.

Ndimubanzi, P. C., Carabin, H., Budke, C. M., Nguyen, H., Qian, Y.-J., Rainwater, E., Dickey, M., Reynolds, S., \& Stoner, J. A. (2010). A systematic review of the frequency of neurocyticercosis with a focus on people with epilepsy. PLoS Neglected Tropical Diseases, 4, e870.

Ngowi, H. A., Kassuku, A. A., Carabin, H., Mlangwa, J. E. D., Mlozi, M. R. S., Mbilinyi, B. P., \& Willingham, A. L. (2010). Spatial clustering of porcine cysticercosis in Mbulu District, Northern Tanzania. PLoS Neglected Tropical Diseases, 4(4), e652. https://doi.org/10.1371/journal.pntd.0000652.

Ngowi, H. A., Kassuku, A. A., Maeda, G. E. M., Boa, M. E., Carabin, H., \& Willingham, A. L. (2004) Risk factors for the prevalence of porcine cysticercosis in Mbulu District, Tanzania. Veterinary Parasitology, 120, 275-283.

Pondja, A., Neves, L., Mlangwa, J., Afonso, S., Fafetine, J., Willingham, A. L., Thamsborg, S., \& Johansen, M. V. (2012). Use of oxfendazole to control porcine cysticercosis in a high-endemic area of Mozambique. PLoS Neglected Tropical Diseases, 6 , e1651.

Sciutto, E., Martínez, J. J., Villalobos, N. M., Hernández, M., José, M. V., Beltrán, C., Rodarte, F., Flores, I., Bobadilla, J. R., Fragoso, G., Parkhouse, M. E., Harrison, L. J. S., \& Aluja, A. S. D. (1998). Limitations of current diagnostic procedures for the diagnosis of Taenia solium cysticercosis in rural pigs. Veterinary Parasitology, 299-313.

Sikasunge, C. S., Johansen, M. V., Willingham, A. L., Leifsson, P. S., \& Phiri, I. K. (2008). Taenia solium porcine cysticercosis: Viability of cysticerci and persistency of antibodies and cysticercal antigens after treatment with oxfendazole. Veterinary Parasitology, 158, 57-66.

Thirumalai, T., Kelumalai, E., Senthilkumar, B., \& David, E. (2009). Ethnobotanical study of medicinal plants used by the local people in Vellore District, Tamilnadu, India. Ethnobotanical Leaflets. https://opensiuc.lib.siu.edu/ebl/vol2009/iss10/10.

Torgerson, P. R., Devleesschauwer, B., Praet, N., Speybroeck, N., Willingham, A. L., Kasuga, F., Rokni, M. B., Zhou, X. N., Fèvre, E. M., Sripa, B., Gargouri, N., Fürst, T., Budke, C. M., Carabin, H., Kirk, M. D., Angulo, F. J., Havelaar, A., \& de Silva, N. (2015). World Health Organization estimates of the global and regional disease burden of 11 foodborne parasitic diseases, 2010: A Data Synthesis. PLOS Medicine, 12, e1001920.

van Wyk, B. E., \& van Staden, J. (2002). A review of ethnobotanical research in southern Africa. South African Journal of Botany, 68, 1-13.

Cite this article: Kabululu ML, Boa ME (2021). Validating efficacy of Sericocomopsis hildebrandtii, Carissa edulis, and Ximenia americana in treating Taenia solium cysticercosis in pigs: A randomized controlled trial Experimental Results, 2, e36, 1-12. https://doi.org/10.1017/exp.2021.29 


\section{Peer Reviews}

\section{Reviewing editor: Prof. Martin Michaelis}

University of Kent, School of Biosciences, Canterbury, United Kingdom of Great Britain and Northern Ireland, CT2 7NJ

This article has been accepted because it is deemed to be scientifically sound, has the correct controls, has appropriate methodology and is statistically valid, and has been sent for additional statistical evaluation and met required revisions.

doi:10.1017/exp.2021.29.pr1

Review 1: Validating efficacy of Sericocomopsis hildebrandtii, Carissa edulis and Ximenia americana in treating Taenia solium cysticercosis in pigs: A randomized controlled trial

Reviewer: Dr. Pierre Dorny

Institute of Tropical Medicine (ITM), Belgium

Date of review: 15 July 2021

(C) The Author(s), 2021. Published by Cambridge University Press. This is an Open Access article, distributed under the terms of the Creative Commons Attribution licence (http://creativecommons.org/licenses/by/4.0), which permits unrestricted re-use, distribution and reproduction, provided the original article is properly cited.

Conflict of interest statement. Reviewer declares none

Comments to the Author: Interesting manuscript with promising results on the efficacy of Sericocomopsis hildebrandtii. Overall, the paper is well written and documented. It would have been nice to include a Oxfendazole treatment group (positive control)

Some major remarks pertain to the description of the methods and on the results and their interpretations.

M\&M:

L90: Please provide some details on how the pigs were kept during the study (housing, group/ individual, feeding, ...)

L91: can you give more details on the weight of the pigs? They were all given the same dose of herbal extractions while the body weight may have been different.

Results:

L132: "...specific effect of the herbal materials": what could be these specific effects?

L141-2: Very strange that no degenerated cysts were found in muscles and organs (other than the brain) of animals in the $\mathrm{T} 1$ group. It often takes more than 16 weeks for cysticerci to completely disappear after treatment. (same remark for L170-4 in Discussion)

Other comments:

L30: "infected" naturally infected

Fig 1: correct "21 pigs not included because due to ..."

L184-5: “... counts, but the reduction was not statistically significant.": if the reduction was not significant, it means that there is no reduction. Do also observe that the cyst numbers cannot be the same in all groups. 


\section{Score Card}

Presentation

Is the article written in clear and proper English? (30\%)

Is the data presented in the most useful manner? (40\%)

Does the paper cite relevant and related articles appropriately? (30\%)

Context

5.0

Does the title suitably represent the article? (25\%)

Does the abstract correctly embody the content of the article? (25\%)

Does the introduction give appropriate context? (25\%)

Is the objective of the experiment clearly defined? $(25 \%)$

Analysis

Does the discussion adequately interpret the results presented? (40\%)

Is the conclusion consistent with the results and discussion? (40\%)

Are the limitations of the experiment as well as the contributions of the experiment clearly outlined? $(20 \%)$ 


\title{
Review 2: Validating efficacy of Sericocomopsis hildebrandtii, Carissa edulis and Ximenia americana in treating Taenia solium cysticercosis in pigs: A randomized controlled trial
}

Reviewer: Dr. Gervason Moriasi

Mount Kenya University, Medical Biochemistry, 342-, Thika, Central, Kenya, 01000

Date of review: 10 October 2021

\begin{abstract}
(c) The Author(s), 2021. Published by Cambridge University Press. This is an Open Access article, distributed under the terms of the Creative Commons Attribution licence (http://creativecommons.org/licenses/by/4.0), which permits unrestricted re-use, distribution and reproduction, provided the original article is properly cited.
\end{abstract}

Conflict of interest statement. Reviewer declares none.

Comments to the Author: Title: Should be revised to read "Efficacy of Sericocomopsis hildebrandtii, Carissa edulis, and Ximenia americana in treating cysticercosis in pigs"

Abstract: (1) The methods should be described well. (2) The use of the term 'concoction' is inappropriate. (3) It is not clear how the control pigs were treated.

Introduction: (1) This section should be revised and improved accordingly. (2) Most references are > 10 years old- Updated and current citations should be adopted. (3) The authors should describe the study plants and include information on what is already known about them. (4) It is not clear whether the collection of ethnomedical information of the studied plants was structured according to the conventional standards.

Methods: (1) Did the authors consider bioconservation and biodiversity of the plants since they uprooted them? (2) The authors should describe the conditions of the environment where the pigs were held, and state how they were handled. (3) The study design seems to be a controlled randomised study design and not a randomised controlled trial design as purported. (4) The experimental design should be revised accordingly. They should have individual groups receiving each respective plant and another group receiving the mixture in an appropriate manner. (5) The authors have not described the status of the control pigs or how they were treated or even the type of control. (6) Appropriate statistics ought to be performed.

Discussion: This should be rewritten after addressing the concerns above.

The language should be improved significantly.

\section{Score Card}

Presentation

2.3

Is the article written in clear and proper English? (30\%)

Is the data presented in the most useful manner? (40\%)

Does the paper cite relevant and related articles appropriately? (30\%)

\section{Context}

Does the abstract correctly embody the content of the article? (25\%)

Does the introduction give appropriate context? (25\%)

Is the objective of the experiment clearly defined? (25\%) 
Analysis

1.2

Does the discussion adequately interpret the results presented? (40\%)

Is the conclusion consistent with the results and discussion? (40\%)

Are the limitations of the experiment as well as the contributions of the experiment clearly outlined? (20\%) 